\title{
SHEDding Light ON CUSTOMER REQUIREMENT SPECIFICATIONS, FUNCTIONAL SPECIFICATIONS AND REQUIREMENTS LISTS - How ENGINEERS LEARN THE CORRECT DOCUMENTATION OF REQUIREMENTS
}

\author{
Ilyas Mattmann, Sebastian Gramlich, and Hermann Kloberdanz \\ Institute for Product Development and Machine Elements, TU Darmstadt, Germany \\ mattmann@pmd.tu-darmstadt.de
}

\begin{abstract}
Engineering students face a confusion of requirements and product properties during task clarification in product development projects. As requirements are mainly documented in the form of desired product properties, customer needs and expectations may not be sufficiently considered during the development of new and innovative products.

This paper presents the results of a systematic literature analysis of existing requirement documentation forms and analyses the documentation process as it is taught to engineering students. Requirements are often documented through a tripartite process of translating customer expectations from the customer requirement specification to the functional specification, while the requirements list provides the base for the product development process. The contents of these documents appear theoretically different, however, they are barely distinguishable from each other in practice.

Therefore, the paper provides a new model-based understanding for the documentation of requirements through gradual concretisation of requirements during the product development process, leading gradually from customer needs and expectations to requirements. Engineering students must be able to gradually concretise requirements then document desired product properties to avoid early fixation on specific product properties. Undergraduate and graduate engineering students should be taught to consider requirements according to the proposed approach as it enables prospective engineers already in the early phases of their engineering education to design highly complex technical products. Thus, the model provides a valuable base for formally supported requirements documentation and the systematic determination of product properties.
\end{abstract}

Keywords: Concretisation of requirements : Documentation of requirements : Customer requirement specification : Functional specification : Requirements list

\section{CUSTOMER REQUIREMENT SPECIFICA- TIONS, FUNCTIONAL SPECIFICATIONS AND REQUIREMENTS LISTS}

\subsection{Introduction}

Prospective engineers face confusion during requirements documentation. Requirements should be documented in the requirements list, as they provide the base for every decision made in development processes [1].

Unfortunately, due to indefinite differentiation of requirements and product properties, requirements are mainly documented as product properties when recording the types of requirements lists. They are mainly separated into characteristics and values in requirements documentation. This leads to limited solution neutrality [2], since common product properties are documented in the requirements list without consideration of the link to important customer needs and expectations. The focus on customer needs and expectations is lost because the documented product properties may not map stakeholder intentions.

However, literature shows differentiated customer requirement specifications (CRS), functional specifications (FS) and requirements lists (RL). Terminological differentiation is clear in engineering design research but not in practice, as customer requirement specifications, functional specifications and requirements lists are usually combined into one document, which leads to undifferentiated documented requirements that are no longer referenced to clearly differentiated contractual dependencies that meet customer needs and expectations.

\subsection{Benefits for requirements documentation}

This paper presents the results of an analysis of engineering design science literature that shows the theoretical differentiation of customer requirement specifications and functional specifications that lead in steps to the require- 
ments list. As the content of customer requirement specifications, functional specifications and requirements lists is not clearly distinguishable in practice, the paper focuses on a newly developed model that gradually translates customer needs into requirements. This leads to a new understanding in requirements documentation that should be taught in engineering science as it would enable undergraduate and graduate students to gradually refine requirements and consider the newly developed approach in practice. They could then differentiate requirements and desired product properties in the documentation process.

\section{THE SUBTLE DIFFERENCES BETWEEN REQUIREMENTS DOCUMENTS}

\subsection{Processes leading to the requirements list}

As proposed in literature on engineering design science, requirements are documented through a tripartite process of translating customer expectations from the customer requirement specification to the functional specification, while requirements in the requirements list provide a base for the product development process [7] (Fig. 1). The contents of these documents appear theoretically different, however they are barely distinguishable from each other in practice.

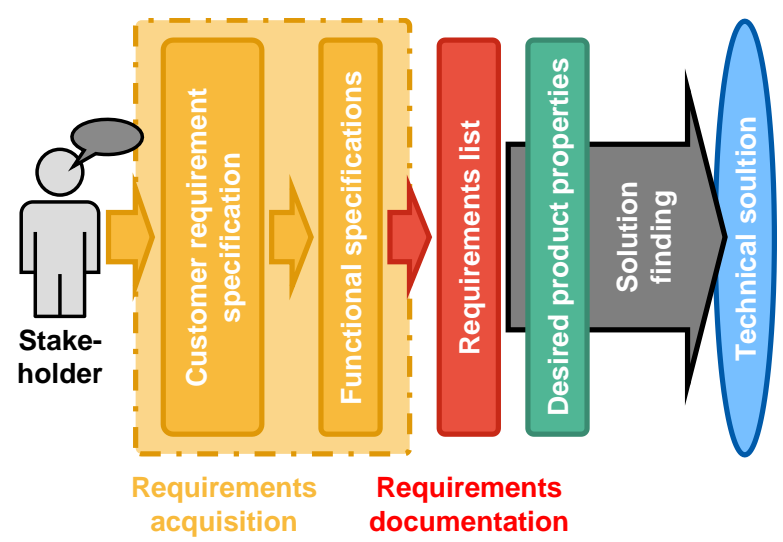

Fig. 1. Derivation of the requirements list throughout development processes

Requirements lead to the determination of desired product properties during the entire product development process. Product designers have to extract the essential requirements through interpretation of customer needs [8], desires, and expectations, as desired product properties have to be determined in a way that best fits the acquired requirements.

As recommended by Ehrlenspiel and Meerkamm [3], the requirements list is the main result of development activities. Customer needs are translated into binding contracts. The requirements list is extracted according to scope statements documented in the functional specification (Fig. 2). The requirements list is directly derived from customer specifications and the functional specification. Requirements that are derived from customer requirement specifications refer directly to customer needs and expectations of the technical product to be developed, whereas requirements that are derived from the functional specification are extended in meaning to include possible intended solutions, which may restrict technical solutions due to internal realisation restrictions.

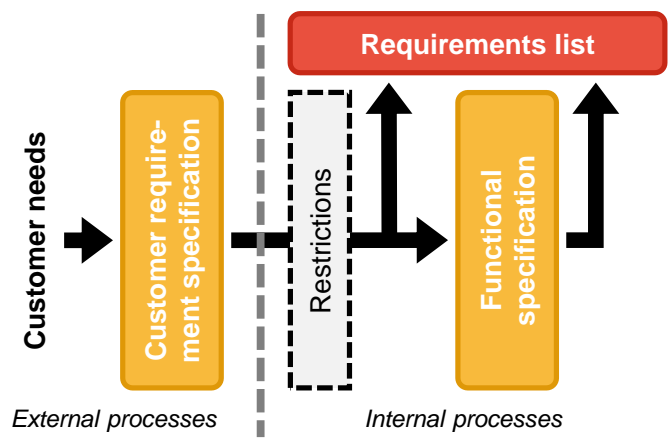

Fig. 2. Derivation of the requirements list according to Ehrlenspiel and Meerkamm [3]

Lindemann [6] highlights the written documentation of requirements as a central prerequisite to control, validate and track requirements. In his definition, requirements are development goals that contain all information in the development process. Requirements are gained in two steps: Customer requirements refer to the customer requirement specification. They are the foundation for the contract between customer and company. Within the functional specification, they are extended by company internal restrictions, leading to the functional specification (Fig. 3).

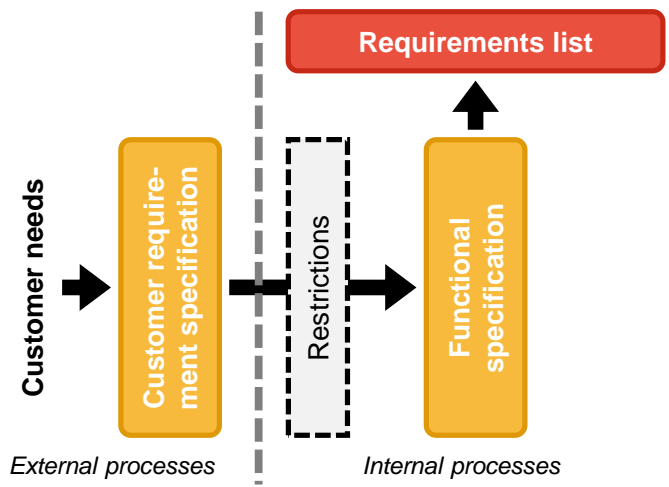

Fig. 3. Derivation of the requirements list according to Lindemann [6]

Feldhusen and Grote [4] emphasise that requirements lists may be electronic and software-based to simplify the interface between companies involved in the development process. As per other authors, Feldhusen and Grote doc- 
ument characteristics with their appropriate values in the requirements list, which is equated with the functional specification. The requirements list is seen as further development of previous documents [4] to guarantee best fit with stakeholder interests in development processes. Customer requirement specifications are developed in preoffer and offer phases, which are proceeded by step-bystep concretisation during the development process, leading to the requirements list (Fig. 4).

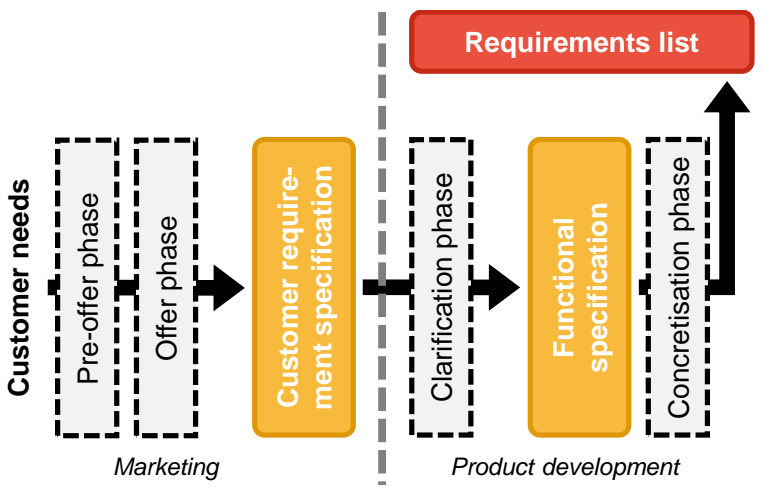

Fig. 4. Derivation of the requirements list according to Feldhusen and Grote [4]

According to Ulrich and Eppinger [8], requirements documentation is equivalent to the total sum of requirements due to their description using appropriate values. Initial documentation, also called target specification, is developed based on identified customer needs. Target specifications include an initial concept of the technical product to be developed. However, a second document, the final specification, is developed with the customer that contains the developable version of the requirements list (Fig. 5). Thus, the target specification is oriented towards the market and external stakeholders to guarantee a property-based description of development goals. The target specification refers to the first version of the requirements list, which focuses on internal aspects for the realisation of the technical product to be developed.



Fig. 5. Derivation of target and final specifications according to Ulrich and Eppinger [8]

\subsection{Differences and Commonalities - Practice vs. Theory}

As shown in the previous section, all processes have major commonalities. In most cases, the requirements list is derived from a separate process: first, documentation of what the customer wants to have in the customer specification document followed by the mapping of realisation possibilities, which are documented in the functional specification. Requirements are documented through a tripartite process of translating customer expectations from the customer requirement specification to the functional specification, while the requirements list provides the base for the product development process.

Functional specifications and requirements lists often have the same content in practice. Customer expectations that are documented in the customer specification document are thus binding as requirements. Development goals are documented freely and do not have to have the same strict requirements formalisation.

\section{NEW MODEL UNDERSTANDING FOR REQUIREMENTS DOCUMENTATION}

Engineering students mostly use checklists, product environment analysis, and process analysis [7], and refer to documented product properties of similar technical products that have been developed in the past for the development of requirements lists. However, requirements documentation is equivalent to the final documentation of desired product properties. Originally focused customer needs and expectations are lost, as most engineers focus on technical skills during engineering education rather than on non-technical yet valuable skills [5].

\subsection{Gradual concretisation of requirements}

Because differentiation between customer requirement specifications, functional specifications and requirements lists is not applied in practice and barely distinguishable in engineering design science, the new model-based approach combines the tripartite document perspective and leads to gradually concretised requirements documentation (Fig. 6), which forms the interface between the requirement acquisition process and the determination of desired product properties. The requirements space contains the entirety of requirements throughout the development process.

Requirements are differentiated according to their compliance with the requirement acquisition process and desired product properties. As customer needs and expectations are gathered during the acquisition process, some requirements are more related to the original customer needs and expectations than others. 


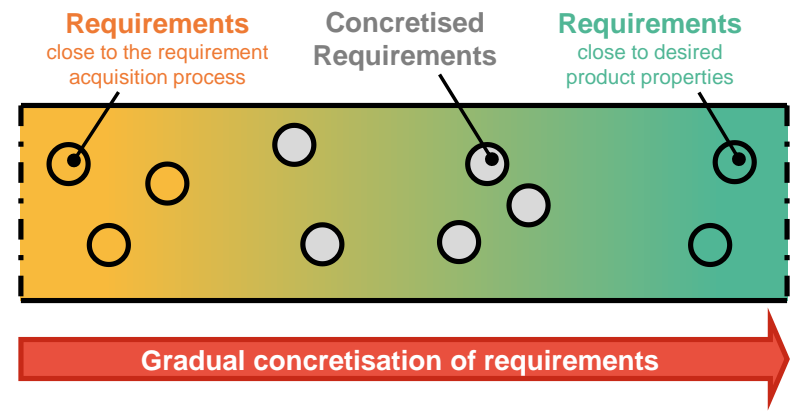

Fig. 6. Model-based approach for gradual requirements documentation

As the development process proceeds, requirements are gradually concretised according to functionality restrictions that the technical product has to fulfil. In this process, requirements have no underlying formalisation and are gradually transferred into requirements that are similar to desired product properties, which may consist of characteristics and values. In these cases, requirements are present according to their formalisation as desired product properties, although they differ in their content and prioritisation.

\subsection{Definition by cases during the gradual con- cretisation of requirements}

Requirements can be aggregated, concretised and specified (Fig. 7). Aggregated requirements result from two or more requirements that are more related to the requirement acquisition process.

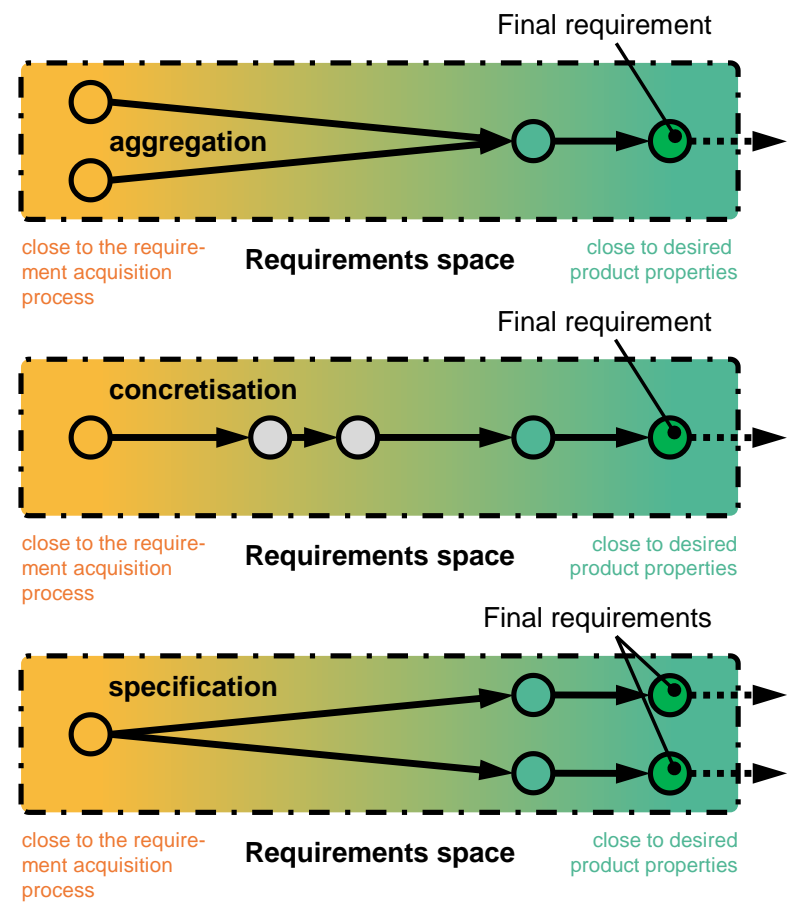

Fig. 7. Gradual concretisation of requirements
Requirements related to customer needs and expectations may be concretised in their content during the ongoing development process. Specified requirements are closer to desired product properties. Thus, three cases may be distinguished during the transformation of requirements into desired product properties.

First, requirements are acquired using company external requirement acquisition processes (problem statement, customer needs and customer requirement specifications). Product designers formalise the acquired information. As customer expectations are often formulated narratively, these requirements must be translated into the language of product designers [2]. Such requirements are considered closer to the acquisition process (Fig. 8, case 1).

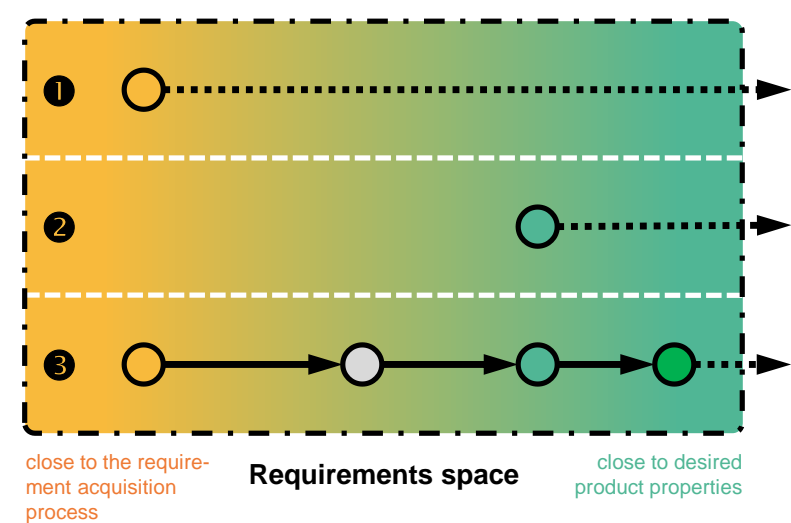

Fig. 8. Definition by cases for the gradual concretisation of requirements

Second, requirements that are acquired from company internal requirement acquisition processes (e.g. functional specifications) have to be formalised. The translation into product designer language has already been accomplished (Fig. 8, case 2). Finally, requirements underpin formalisation and are therefore close to desired product properties. However, other requirements may not be in this state, thus necessitating gradual concretisation processes that lead to the determination of desired product properties (Fig. 8, case 3 ).

Each requirement can be assigned to the requirements space according to its degree of formalisation; whether it is closer to the acquisition process or closer to formalisation of desired product properties. The more that requirements are related to the degree of formalisation of desired product properties, the less the room for interpretation. Requirements gradually approach to the formalisation of desired product properties. Requirements close to the acquisition process need further steps to be concretised, aggregated and specified. The goal should be to reach maximum finalised and concretised requirements within the requirements space that can be easily used to determine desired product properties of the technical product to be developed.

CEEA15; Paper 30 


\section{CONCLUSIONS}

Requirements are often documented through a tripartite process of translating customer expectations from the customer requirement specification to the functional specification, while the requirements list provides the base for the product development process.

The tripartite distinction disappears in practice due to the non-differentiable document content, which leads to early solution fixations during the determination of desired product properties. Requirements have to be documented along the entire development process, starting from customer needs and expectations that are gradually formalised and refined into requirements. Requirements have different stages, whether they are related to the acquisition process or the concretisation process and formalisation into desired product properties. A continuum of requirements exists within these two limitations that leads to a gradual concretisation of requirements.

Thus, a valuable base for formally supported requirements documentation and the systematic determination of product properties is provided, as the proposed approach enables prospective engineers to design highly complex technical products already in the early phases of their engineering education.

\section{Acknowledgements}

Thanks to the German Research Foundation (DFG) for funding this work (Collaborative Research Grant CRC 666).

\section{References}

[1] Amaresh Chakrabarti, Engineering Design Synthesis: Understanding, Approaches and Tools. London, UK: Springer, 2002, 49 pp. \{ISBN 1-85233-492-4\}

[2] Wolfgang E. Eder and Stanislav Hosnedl, Design Engineering: A Manual tor Enhanced Creativity. Boca Raton, FL: CRC Press, 2008, 223 pp. \{ISBN: 978-1-4200-4765-3\}

[3] Klaus Ehrlenspiel and Harald Meerkamm, Integrierte Produktentwicklung: Denkabläufe, Methodeneinsatz, Zusammenarbeit. Munich, Vienna: Carl Hanser Verlag, 2013 (5th ed.), 391 pp. \{ISBN: 978-3-446-43548-3\}

[4] Jörg Feldhusen and Karl-Heinrich Grote, Pahl/Beitz Konstruktionslehre: Methoden und Anwendung erfolgreicher Produktentwicklung. Berlin, Heidelberg: Springer Vieweg, 2013 (8th ed.), 319 pp. \{ISBN: 978-3-642-29568-3\}

[5] Domenico Grasso and Melody Brown Burkins, Holistic Engineering Education: Beyond Technology. New York, Dordrecht, Heidelberg, London: Springer Science+Business Media, 2010, 39 pp. \{ISBN 978-1-4419-1392-0\}

[6] Udo Lindemann, Methodische Entwicklung technischer Produkte: Methoden flexibel und situationsgerecht anwenden. Berlin, Heidelberg: Springer-Verlag, 2009 (3rd ed.), 108 pp. \{ISBN: 978-3-642-01422-2\}

[7] Gerhard Pahl, Wolfgang Beitz, Jörg Feldhusen, and KarlHeinrich Grote, Engineering Design: A Systematic Approach. London, UK: Springer, 2007 (3rd ed.), 145 pp. \{ISBN: 978-1-84628-318-5\}

[8] Karl T. Ulrich and Steven D. Eppinger, Product Design and Development. New York, NY: McGraw-Hill/Irwin, 2008 (4th ed.), 73 pp. \{ISBN: 978-007-125947-7\} 